\section{(A) OPEN ACCESS}

\title{
Returning incidental findings from genetic research to children: views of parents of children affected by rare diseases
}

\author{
Erika Kleiderman, ${ }^{1}$ Bartha Maria Knoppers, ${ }_{1}^{1}$ Conrad V Fernandez, ${ }^{2}$ Kym M Boycott, ${ }^{3}$ \\ Gail Ouellette, ${ }^{4}$ Durhane Wong-Rieger, ${ }^{5}$ Shelin Adam, ${ }^{6}$ Julie Richer, ${ }^{7}$ Denise Avard ${ }^{1}$
}

${ }^{1}$ Centre of Genomics and Policy, McGill University, Montreal, Quebec, Canada ${ }^{2}$ Faculty of Medicine, Departments of Pediatrics and Bioethics, Dalhousie University, Halifax, Nova Scotia, Canada ${ }^{3}$ Children's Hospital of Eastern Ontario Research Institute, University of Ottawa, Ontario, Canada

${ }^{4}$ Regroupement Québécois des Maladies Orphelines, Sherbrooke, Quebec, Canada ${ }^{5}$ Institute for Optimizing Health Outcomes, Canadian Organization for Rare Disorders, Toronto, Ontario, Canada

${ }^{6}$ Department of Medical Genetics, University of British Columbia, Vancouver, British Columbia, Canada

${ }^{7}$ Department of Genetics, Children's Hospital of Eastern Ontario, Ottawa, Ontario, Canada

\section{Correspondence to} Erika Kleiderman, Faculty of Medicine, Department of Human Genetics, Centre of Genomics and Policy, McGill University, 740 Dr Penfield Avenue, 5th Floor, Suite 5200, Montreal, Quebec, Canada H3A 0G1; erika.kleiderman@ mail.mcgill.ca

Received 11 June 2013 Revised 8 November 2013 Accepted 15 November 2013 Published Online First 19 December 2013

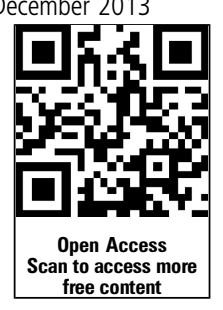

\section{CrossMark}

To cite: Kleiderman $E_{\text {, }}$ Knoppers BM,

Fernandez CV, et al. J Med Ethics 2014;40:691-696.

\begin{abstract}
Purpose To explore parental perceptions and experiences regarding the return of genomic incidental research findings in children with rare diseases.

Methods Parents of children affected by various rare diseases were invited to participate in focus groups or individual telephone interviews in Montreal and Ottawa. Fifteen participants were interviewed and transcriptions were analysed using thematic analysis.

Results Four emergent themes underscored parental enthusiasm for receiving incidental findings concerning their child's health: (1) right to information; (2) perceived benefits and risks; (3) communication practicalities: who, when, and how; and (4) service needs to promote the communication of incidental findings. Parents believed they should be made aware of all results pertaining to their child's health status, and that they are responsible for transmitting this information to their child, irrespective of disease severity. Despite potential negative consequences, respondents generally perceived a favourable risk-benefit ratio in receiving all incidental findings.

Conclusions Understanding how parents assess the risks and benefits of returning incidental findings is essential to genomic research applications in paediatric medicine. The authors believe the study findings will contribute to establishing future best practices, although further research is needed to evaluate the impact of parental decisions on themselves and their child.
\end{abstract}

\section{INTRODUCTION}

While recent discussions on the issue of the return of results (including 'incidental findings' (IF)) in the context of research have achieved international notoriety in the ethical, legal and social implications (ELSI) literature, the views of minors or parents in the paediatric context have been neglected.

The current return of results debate identifies three areas of general consensus. First, the return of general research results is a sine qua non-albeit, an obligation whose contours and methodologies require further refinement. Second, the term IF may be inappropriate where whole genome/exome sequencing technologies are employed. ${ }^{1}$ Since the goal of these techniques is to expose the genome, the findings can only be incidental with respect to the primary research objectives and question. Third, professional societies largely agree that clinically significant and medically actionable findings should be returned if the participant so desires, even where the findings are outside of the research objectives. However, to this latter point, there is considerable debate as to how carefully the researcher should search for these findings; what threshold of significance warrants return; for how long does the researcher's responsibility to disclose persist; and what are the professional duties to disclose pertinent genetic information to a participant's biological family members.

Consensus dissolves when considering the roles of carrier status, reproductive implications and familial interests in the specific context of paediatric research. The recent $\mathrm{P}^{3} \mathrm{G}$ (Public Population Project in Genomics and Society) international Statement on the Return of Whole-Genome Sequencing Results in Paediatric Research attempts to draw a nuanced, yet balanced, position on these roles based on the best interests of the child. ${ }^{2}$ The Statement, however, seemingly does not reflect the views of parents as we describe below. Indeed, it is questionable whether the views or interests of minors prevail over the 'rights' of parents to decide what, and under what circumstances, results should be returned.

Although next-generation sequencing is likely to become a crucial clinical diagnostic tool, it is not yet a standard of care in Canada and other industrial countries. Currently, it is used primarily in a research context, thereby providing a vehicle for acquiring an evidence base on the impact of such technologies. This is especially true in the cases of rare childhood genetic disorders, as the increased availability of next-generation sequencing helps to reliably identify gene variants and to more rapidly diagnose rare diseases. ${ }^{3}{ }^{4}$ Parents of children with a family history of rare disease may hold different positions on genetic testing than parents of healthy children. On this point, the former tend to be more accepting. ${ }^{5}$ Receiving genetic results that can effectively end the diagnostic odyssey is paramount for them, and come as a great source of relief. ${ }^{6}$ However, returning unanticipated results from a genetic research study becomes further complicated when participants are too young to provide fully informed consent." Thus, "many parents struggle to know when, how and what to tell their children about [...a] genetic risk [discovered in a research context] because they fear causing distress". ${ }^{7}$

Given this ambiguity, understanding parental perspectives on IF is critical to drafting policies that govern what types of information can, or ought to, be returned in the context of rare childhood disease 
Table 1 Dimensions of illness presented in the vignettes

\begin{tabular}{|c|c|c|c|c|}
\hline & \multicolumn{4}{|l|}{ Dimensions of illness } \\
\hline & Likelihood of development & Clinical severity & Timing of clinical onset & Treatment/prevention options \\
\hline \multicolumn{5}{|l|}{ Genomic disorders } \\
\hline Duchenne muscular dystrophy (DMD) & $\begin{array}{l}\text { Lower in girls } \\
\text { Higher in boys }\end{array}$ & High & Childhood onset & Surveillance \\
\hline Learning Difficulty & Variable likelihood & Low to high & Early & Treatable \\
\hline Huntington's Disease & High & High & Adult onset & Untreatable \\
\hline Carrier cystic fibrosis (CF) & No risk of disease & NA & $N A^{*}$ & Reproductive/family planning \\
\hline
\end{tabular}

Spectrum of issues

Who? $\quad$ Who should communicate the incidental findings to you? Why?
$\begin{aligned} & \text { How? } \\ & \text { What? }\end{aligned} \quad$ Would you like to know these incidental findings? Why?
$\begin{array}{ll}\text { Responsibility? } & \text { Wo you have a responsibility to tell other family members (of this incidental finding) who might carry a risk for the condition? } \\ \text { Benefits/Risks? } & \text { What kind of additional problems (besides your child's health) can you foresee in receiving this incidental finding? } \\ \text { Psychosocial } & \text { What would be the emotions and feelings involved in receiving this incidental finding? Do you think there is a need for social support? Who should } \\ \text { aspects? } & \text { provide this support? }\end{array}$
*In general, carrier status implies that the individual does not have symptoms nor will he/she develop the disease, but such status has reproductive implications for the parents, his/her
siblings or for the child when an adult.

research. A guiding framework for this approach is the Family Systems Genomic Illness (FSGI) model developed by Rolland. ${ }^{8}$ The model examines "the relationship between individual and family dynamics with genomic disorders" $"$ and draws distinctions between four core issues surrounding the typology of genomic illness: the certainty of a genetic condition, the severity of the condition, the timing of onset, and whether an effective medical intervention exists. Although several studies have explored parental perspectives regarding the return of general and individual research results in the paediatric context, ${ }^{9}{ }^{10}$ none consider these perspectives as they relate to the illness dimensions raised in the FSGI model. Our study analyses how the type of illness influences parental decisions to receive IF concerning their child's genetic disorder. We use four specifically designed scenarios that reflect the FSGI dimensions to gauge parental perceptions (table 1). We anticipate these study findings will contribute to the development of more nuanced regulatory guidelines that appreciate the variety of potential clinical and social impacts for affected children and their families.

\section{MATERIALS AND METHODS Study participants}

Fifteen parents of children affected by an array of rare diseases took part in the study (table 2). Examples of the rare diseases encountered in the study include spastic paraplegia type 11, Alagille syndrome, hyperchylomicronemia, Beckwith-Wiedemann syndrome and Loeys-Dietz syndrome. All parents who initiated contact, after hearing about the study, also participated in the study. Purposeful sampling was employed to recruit study participants. Flyers were posted on the Canadian Organization for Rare Disorders and the Regroupement Québécois des Maladies Orphelines websites (criterion), in genetics clinics at two children's hospitals (Montreal Children's Hospital and Children's Hospital of Eastern Ontario) (criterion), and through word of mouth (snowball).

\section{Data collection}

Data collection spanned between March and August 2012. We chose qualitative methods to engage parents in in-depth discussions concerning their decision to receive IF pertaining to their child's health status. ${ }^{11}$ We conducted two focus groups (three participants each) and nine open-ended telephone interviews (until saturation was reached ${ }^{12}$ ). The authors supplemented focus groups with telephone interviews due to poor response, which can be attributed to parental time constraints in caring for their child's health needs. This was consistent with the literature that suggested a mixed methods approach to data collection can further enrich the findings. ${ }^{13}$

Table 2 Participant demographics

\begin{tabular}{lcc}
\hline Demographic & N=15 & Per cent \\
\hline Gender of parents & & \\
$\quad$ Male & 2 & 13.3 \\
Female & 13 & 86.7 \\
Age of parents & & \\
20-30 years old & 0 & - \\
31-40 years old & 8 & 53.3 \\
41-50 years old & 5 & 33.3 \\
51-60 years old & 2 & 13.3 \\
Education of parents & & \\
Grade school (up to grade 8) & 0 & - \\
High school (up to grade 12) & 2 & 13.3 \\
College-community, nursing etc & 1 & 63.7 \\
University & 11 & 6.7 \\
Other & 1 & 53.3 \\
Gender of child & & 46.7 \\
Male & 8 & \\
Female & 7 & 46.7 \\
Age of child & & 40.0 \\
Under 7 years old & 7 & 13.3 \\
Between 7 years and 18 years old & 6 & \\
Above 18 years old & 2 & \\
Siblings (affected or healthy) & 90.0 \\
Yes & 6 & \\
No & & \\
\hline
\end{tabular}


Telephone interviews and focus groups were conducted in Montreal and Ottawa, and each lasted approximately $60 \mathrm{~min}$. They were conducted in English (11) and French (4), and were facilitated by a bilingual researcher (DA) and a research assistant (EK). Interviews were audio recorded and transcribed for data analysis, and translated solely for the purpose of integrating the quotes into the article (denoted by the mention beside the quote).

\section{Interview guide development}

The moderator's guide was developed based on a review of the literature. The questionnaire was then presented and piloted by a multidisciplinary steering team. Their comments were incorporated into the guide prior to ethics approval and data collection.

We developed four hypothetical vignettes to explore parental decision making in receiving IF based on variations in disorder characteristics (table 1). The vignettes were provided to participants ahead of time, and consent was obtained upon arrival at the focus group and verbally over the telephone (a signed copy was sent by mail).

\section{Data analysis}

Responses to interviews and focus groups were coded by EK and DA, and analysed using a constant comparative method to identify emergent themes. ${ }^{14}$ The coding strategy was mixed, using thematic analysis, while predetermined codes were developed from the interview guide and the literature review. EK and DA coded independently to achieve analytical rigour, to reduce subjectivity and to ensure accuracy as well as intercoder reliability. Both used the NVivo10 software and consensus was reached by discussion.

\section{RESULTS}

\section{Characteristics of respondents}

Participant demographics are displayed in table 2.

\section{Overall wish to receive incidental findings}

There were notable similarities in responses across the various illness types presented in the vignettes, although some distinctions were observed and are noted accordingly.

In general, respondents expressed an overwhelming interest in receiving the child's research results.

What I know makes me feel better. It's what I don't know [that] is what I don't like. [...] I want to know everything. [...] I want to know what possibly she, or any of us could have; to enable us to make better decisions in the future. (20120605)

However, one respondent mentioned they would prefer not to know the results immediately if a disorder did not directly affect the child, for example carrier status, as it would negatively impact the child (ie, changes the dynamics of the relationship) and prefer to let life take its course.

They don't have anything to worry about in the next year, if it's just a child who is a carrier. It's more when the child is an adult and wants to start a family of their own. (20120510, Carrier CF)

Analysis of participant responses to the vignettes and their strong desire for comprehensive information regarding their child's health status identified a wide range of issues that can be grouped under four core themes (box 1).

\section{Parental right to information}

As parents, respondents maintained that they had a 'right to know' their children's results, to be more aware of clinical risks, to improve future decision making (eg, reproductive choices) and to take appropriate responsibility for their children's health.

\section{Box 1 Core issues raised by respondents}

\section{Core issues}

1. Parental right to receive incidental findings

2. Perceived benefits and risks of receiving incidental findings

3. Communication practicalities: Who, when and how?

- Parent to family

- Expert to parent

4. Service needs to promote the communication of incidental findings

We have a right to know our medical condition, our state of health and even for our future generations too. [...] I would say: 'Well why didn't you tell me?' It's more for awareness of anything and not only that but the awareness for the future too. (20120321-04)

Some respondents wanted to exercise a certain amount of control over what was deemed "relevant" information regarding their child, in order to provide the best possible care.

I think every parent is always interested in how it would affect their own [children], and if there are other cases that are similar you can extrapolate your prognosis for your own child hopefully. (20120501)

In particular, parents were less confident they would want to know the results if the disorder was a highly penetrant and fatal adult-onset illness, such as Huntington's disease, because of implications on day-to-day living.

I would want to know [any results pertaining to my child], but would you change your lifestyle, would you enjoy your day a little more, or would you just worry about it until you got to that step? And then [...there is] always a chance they could develop [a] treatment. [...] I would want to know but it's less obvious to me. (20120501, Huntington's)

Furthermore, most respondents supported the right to choose whether to know the carrier status of the child, the primary rationale being that knowing this information would allow them to prepare their children for what may lie ahead:

Part of my job is to help my kid grow up to be a happy healthy adult and well prepared for life. So if I need to know that if they are carrier status they should be okay. (20120509-1, Carrier CF)

Parents were unanimous that researchers have a responsibility to communicate IF, and argued that failing to do so would be irresponsible.

I think it is irresponsible to not divulge information if you knew... you may cause worry but at least you are aware of it and can take steps to either mitigate or do something [about it]. (20120501)

Finally, they expected reciprocity for their participation, reasoning that parents should be informed of any emergent results, regardless of the study's success. This is due to the time they or their child donated and the personal ties to the investigation and questions at hand.

Because you have invested time and effort into the study and even if nothing came out of it, I wouldn't want to be left not knowing if they found something or didn't find something. (20120509-2) 


\section{Perceived benefits and risks}

When asked about benefits, all respondents felt that 'knowing' and 'receiving' the IF was empowering. It rendered them better equipped to plan and support the child, to take proactive financial and health measures and to make informed decisions regarding their child's future health (eg, do something about it).

We have to take responsibility for our healthcare management and we have to be our own advocate. [...] If I do not know what I am dealing with then I cannot set up my appropriate strategy and take care of my child. (20120509-1)

By contrast, few respondents expressed concerns about insurability and employability:

You create financial challenges for the family. You now create a burden...it opens up issues of insurability of that patient. It opens up issues of employability of the patient. (20120509-1)

Communication practicalities: who, when and how?

Overall, respondents supported honest and open communication with their children.

As soon as we found out, I made sure that she was also informed about her illness; [...] Nothing was hidden or kept secret from her. (20120314-01) [translated]

\section{Expert to parent: possible approaches}

Respondents appreciated honest inputs from clinicians, and felt that effective communication in the disclosure of IF centred on genetic expertise and access to clinical resources.

It is relating to genetics [...] the geneticist would be able to answer more specific questions regarding genetics [...] They just have the expertise in it. (20120509-2, DMD)

They indicated that the physician should present information that is clear and concise, while avoiding medical jargon.

The geneticist will tell us in very scientific terms what they found and then they will interpret and put it into plain language so we can understand it a bit better and they may even elaborate on that so that it gives us even more context and helps us to understand. (20120510)

Parents identified challenges in communicating different types of results. In general, they felt that consultation with a health professional about IF should be commensurate with disease severity, as the Huntington's disease case illustrates. Parents preferred inperson communication as they felt it showed empathy and reinforced the trust in patient-physician relationships.

Absolutely verbal. [...] It would almost seem uncaring just to receive it on a piece of paper. (20120605, Huntington's)

It should be done in person because, depending on the result, you may want to know more. (20120314-02, DMD) [translated]

\section{Parent to family: possible approaches}

Respondents drew a distinction between communicating IF to their children verses other family members. Most saw it as the parent's responsibility to explain the findings to their children, and stated that they are the best suited to introduce the information gently because it may be frightening or too complicated for their child to understand.

[It is the] parents' responsibility to explain it to [...their children] in a way, in small chunks [...]-when and where it's appropriate. [...] I mean I think parents are probably best in that case to break the news or at least explain it in a way that they can come to terms with it. (20120510, Huntington's)

Most respondents felt a similar responsibility to communicate results to the extended family.

If it impacts on my family, my relatives; my responsibility is to make them aware of the findings [...]. Then it's their responsibility to do something with this. (20120515)

In addition to communication styles, respondents all agreed that timing also remained a challenge. They felt that disclosure should vary based on the child's evolving capacity (eg, age, maturity, relationship status). However in general, parents wanted to find out sooner rather than later in order to maximise time to prepare for lifestyle adaptations.

To prepare for care, to prepare the family for emotional support, to get a good network around you, to get a team [of doctors] around you, and get what you need and be proactive in your child's care. (20120321-02)

They also argued that their children should have the option to refuse IF once they have reached adulthood, and that all parents should respect this decision.

[...] At 18 [...the child] can tell you to bug off and I don't want to know about it, this is their choice, or they could say yes lets go have that discussion. (20120509-1, Carrier CF)

\section{Additional support to promote the communication of incidental findings}

There was an overwhelming desire for additional support following the return of incidental information.

It's what I call the 'shock phase'. You are now told the highlighted bolded areas of your page very quickly [and] this is like getting hit over the head with a ton of bricks. So you need somebody that is going to help you walk through the emotional components so that you can get back to being functional. [...] You're not [in] a functional mode; you are [in] an emotional mode. (20120509-1)

Parents mentioned a variety of support services to promote the communication of genomic research results, including counsellors, psychologists, family, friends, support groups and the medical community.

They should be offering support by giving you a social worker's business card or something or offering to set up an appointment or giving you a list of resources or websites to use. (20120510)

Conducting internet research provided parents with a wealth of information on the diagnosis-a kind of support in itselfhowever most parents argued that personal consultations with clinicians were preferable.

I would want to do as much research as possible...So to me, knowledge is power. [...] I could always be following up and researching for that just in case moment $[. .$.$] if and when it does$ happen. (20120605)

\section{DISCUSSION}

\section{Wanting to know everything}

The literature holds that parents should be adequately informed of the possibility for uncovering IF, and of the option to receive these, during the course of genetic studies. ${ }^{15}{ }^{16}$ In general, respondents showed enthusiasm for receiving IF independent of the nature of the four illness scenarios provided in our study. Despite this enthusiasm, some acknowledged that this choice could be difficult. As anticipated, communicating the 
inevitability of an "untreatable adult-onset disorder" (eg, Huntington's disease) elicited the greatest concern.

The literature supports that parents and their children (when able) express an interest in receiving genetic information pertaining to their own health or that of their child. ${ }^{17-20}$ Parents are perceived as the logical informational gatekeepers for their children. ${ }^{16}$ Typically, they will have the child's best interests at heart and want to make the best possible decision with appropriate support, information and, when possible, input from the child depending upon his or her maturity. ${ }^{16} 17$

Ethical concerns arise in the preservation of a child's autonomy and the 'right' to an open future. The 'right' to an open future while not a legal right per se, "prioritizes the future right of children to make their own decisions over the broadly accepted prerogative of parents to make choices that influence the health of their child". ${ }^{17}$ The concept of assent substantiates children's voices in clinical decisions and respects their burgeoning autonomy. ${ }^{2}{ }^{21}$ An engagement approach "suggests that [the autonomy of] children matter[s], but that the final decision will, at least in some cases, be made by the parents". ${ }^{21}$ Ultimately, a balance is needed between a parent's desire to receive IF and the child's best interests. ${ }^{22}$

Respondents did not support the counterargument that the return of research-related IF poses a threat to the child's 'right' to an open future. ${ }^{23-26}$ As such, parental opinions presented in our study neither echo the recommendations of the RMGA Statement of Principles on the Return of Research Results and Incidental Findings, ${ }^{27}$ nor the recent $\mathrm{P}^{3} \mathrm{G}$ international statement ${ }^{2}$ which prioritise the child's best interests and limit testing and disclosure to early-onset and actionable conditions. ${ }^{2} \quad 1926$ Respondents dismissed such criteria in favour of fewer limitations on disclosure.

The American College of Medical Genetics and Genomics ${ }^{28}$ asserts, "a strict nondisclosure policy in paediatric research could deprive subjects [or their parents] of important health information that may be relevant to children before they reach adulthood". ${ }^{19}$ This position leaves open the possibility for carrier and predictive testing in children, ${ }^{17} 29$ including the disclosure of late-onset conditions where there are significant health implications for the family. ${ }^{25}$ Our findings more closely align with this permissive approach. The balancing of "the potential benefits to some family members against the possible harms and loss of autonomy for the affected child"19 needs to consider the best interests of the child, as well as familial benefit ${ }^{2}$ - that is the life context of the child.

\section{Foster greater communication}

Generally, respondents prefer that information be accessiblethat is free of complex medical jargon-and adapted to reflect the type of diagnosis. To them, reciprocal relationship building with clinicians and researchers was consistent with the need for being informed.

Our results confirm that parents feel they bear the ultimate responsibility in assessing what information should be returned, as well as when and how. ${ }^{5} 730$ Respondents urge geneticists to be the main gatekeepers of this information due to their broader knowledge and expertise. They are mindful that feedback depends on the type of illness, and the child's developing maturity and comprehension.

Parents' right to know (or not) genetic information about their children puts into sharp relief that legal and social responsibilities of parenting can sometimes be at odds. Where parents often consider their protective role to extend the duration of a child's life, the legal right to information about them stops, in theory, when the child reaches the age of majority. Some commentators argued that respecting a child's privacy with respect to his/her genetic information should be made in accordance to their developing capacities. ${ }^{21}$ Professionals agreed, "parents serve as surrogate decision makers until children can make their own decision". ${ }^{16}$ As autonomy and cognitive maturity progresses toward adulthood, parents must reassess their roles as information gatekeepers and decision makers. ${ }^{16}$ This is certainly challenging when IF (inevitably) affect the entire family. A family centred model, such as the FSGI, is thus helpful in better understanding how returning IF affects family communication. This model supports and consults "parents as experts in aspects of care of their child as well as developing parents' knowledge, skills and self-efficacy to give care and handle the situation", 31 and encourages parents to communicate with other family members once a formal diagnosis is reached. ${ }^{32}$

\section{Risk-benefit balance}

Our results suggest that respondents believe there is utility in returning IF, as it enables them to cope, facilitate financial and emotional planning, inform future reproductive decisions, and ensure the best possible care for their child. For some, the prospect of receiving such information raised possible negative consequences such as financial burden, insurance and employability. While aware of the possible negative outcomes, respondents all agreed that the benefits of receiving IF outweighed these negative risks.

It is important however, to note that adopting a 'one-size fits all' approach for disclosing such information should be avoided. Parental voice and choice should be represented in determining how IF should be handled in paediatric research. ${ }^{15}$ Providing the necessary support to parents and families throughout the research process is essential. Empirical evidence suggests that parents observe a paucity of these services following a child's diagnosis, which can render the return of IF even more stressful and distressing to families. ${ }^{33}$ One suggested strategy is to use genetic counselling at the time of diagnosis to assist parents with uncertainty. ${ }^{33}$

While this study illustrates issues surrounding IF, none are particularly new. A one-size approach does not fit all. There are nuances in how these issues are perceived, and it is important to recognise that individuals navigate them differently. While most parents want to receive all information necessary to manage their child's health, they submit that many factors come into play in their decision making, including: illness type, definitions of actionability, personal utility, ownership, benefit sharing and right to information. The Rolland model may be useful to investigate how parents navigate the world of IF, and to inform future policy development in highlighting how the certainty, severity, timing and availability of a medical intervention influence risk assessment and decision-making.

\section{Limitations}

Due to their limited time availability, it was particularly difficult to recruit parents of children affected by rare diseases. As a result, small-sized focus groups limited the range of experiences shared; we complemented these with more in-depth individual telephone interviews. We believe, however, the saturation we observed in the thematic analysis is evidence of accurate representation among this group. Because respondents reported on their predicted reactions to hypothetical situations, it is reasonable that certain views might also differ in real clinical situations. Additionally, the study sample was comprised of highly educated participants. Parents were recruited through organisations like the Canadian Organization for Rare Disorders and the Regroupement Québécois des 
Maladies Orphelines and were better supported, experienced less anxiety, and were empowered advocates.

\section{CONCLUSION}

We demonstrate that parents wish to be engaged with clinically relevant findings of genetic research. This allows them to be integrally involved in their child's health and future planning, and is closely associated with increased feelings of support and understanding of the disorder, as well as decreased levels of stress. ${ }^{17}$ Ultimately, effective communication with parents builds trust and empowers them to take on active roles in their child's healthcare. Future research might explore the unique perspectives on the disclosure of genetic information among young people on the verge of majority, as this would permit the exploration of the experiences of those on the other side of the balance: children.

Usefulness of this study and the implications for health professionals: "I think that the genetic community and the genetic counsellor community need to get this feedback from this study to say here is what we learnt in delivering this type of information." (20120509-1)

Acknowledgements The authors thank the Canadian Organization for Rare Disorders (CORD) and the Regroupement Québécois des Maladies Orphelines (RQMO) for their help in the recruitment of participants to this study. The authors also thank Minh Thu Nguyen for her assistance in the recruitment and data collection phases, as well as Vaso Rahimzadeh for her assistance in editing the manuscript.

Contributors EK participated in the collection and analysis of data and the drafting of the manuscript. BMK participated in the conception of the study. KMB and CVF participated in the conception and design of the study. GO and DW-R participated in the recruitment of participants. SA and JR participated in the conception of the study and protocol development. DA participated in the conception and design of the study, the collection and analysis of data, and the drafting of the manuscript. EK wrote the first draft of the manuscript; all authors provided support, comments and critical analysis of the drafts. All authors read and approved the final manuscript.

Funding This project was funded by the Canadian Institutes of Health Research (ClHR) and Genome Canada, as part of the Finding of Rare Disease Genes (FORGE) Canada Consortium (OGI-049). CVF was supported in part by Genome Canada through the IGNITE project, 2010 LARGE-SCALE APPLIED RESEARCH PROJECT COMPETITION 2603 McMaster IGNITE (Orphan Diseases: Identifying Genes and Novel Therapeutics to Enhance Treatment) and the CPCGC (AT1D-131PED; The Canadian Pediatric Cancer Genomics Consortium: Translating Next-generation Sequencing Technologies into Improved Therapies for High-risk Childhood Cancer Project).

\section{Competing interests None.}

Ethics approval Ethics approval was obtained from the McGill University Institutional Review Board.

Provenance and peer review Not commissioned; externally peer reviewed

Open Access This is an Open Access article distributed in accordance with the Creative Commons Attribution Non Commercial (CC BY-NC 3.0) license, which permits others to distribute, remix, adapt, build upon this work non-commercially, and license their derivative works on different terms, provided the original work is properly cited and the use is non-commercial. See: http://creativecommons.org/ licenses/by-nc/3.0/

\section{REFERENCES}

1 Lyon GJ. There is nothing 'incidental'about unrelated findings. Personalized Med 2012:9(2):163-6.

2 Knoppers BM, Avard D, Sénécal K, et al. Return of whole-genome sequencing results in paediatric research: a statement of the $\mathrm{P}^{3} \mathrm{G}$ international paediatrics platform. Eur J Hum Genet 2014;22(1):3-5.

3 Schrader KA, Heravi-Moussavi A, Waters PJ, et al. Using next-generation sequencing for the diagnosis of rare disorders: a family with retinitis pigmentosa and skeletal abnormalities. J Pathol 2011;225(1):12-18.
4 E-Rare Workshop: Ethical aspects of exome and whole genome sequencing studies (WES/WGS) in rare diseases; 2013 January 14, 2013; Tel Aviv, Israel.

5 Dalby S. GIG response to the UK clinical genetics society report "The genetic testing of children". J Med Genet 1995;32(6):490.

6 Groft SC, Posada de la Paz M, eds. Rare diseases_avoiding misperceptions and establishing realities: the need for reliable epidemiological data. Rare Diseases Epidemiology. Part 1. The Netherlands:Springer, 2010:3-14.

7 Metcalfe A, Plumridge G, Coad J, et al. Parents' and children's communication about genetic risk: a qualitative study, learning from families' experiences. Eur J Hum Genet 2011;19(6):640-6.

8 Rolland JS, Williams JK. Toward a biopsychosocial model for 21st-century genetics. Fam Process 2005;44(1):3-24.

9 Fernandez CV, Santor D, Weijer C, et al. The return of research results to participants: Pilot questionnaire of adolescents and parents of children with cancer. Pediatr Blood Cancer 2007;48(4):441-6.

10 Hens $\mathrm{K}, \mathrm{Nys} \mathrm{H}$, Cassiman J-J, et al. The return of individual research findings in paediatric genetic research. J Med Ethics 2011;37(3):179-83.

11 Krueger RA, Casey MA. Focus groups: a practical guide for applied research. 4th edn. Thousand Oaks, CA: Sage, 2009.

12 Mason M. Sample Size and Saturation in PhD Studies Using Qualitative Interviews. 2010

13 Lambert SD, Loiselle CG. Combining individual interviews and focus groups to enhance data richness. J Adv Nurs 2008;62(2):228-37.

14 Patton MQ. Qualitative research and evaluation methods. 3rd edn. Thousand Oaks, CA: Sage Publications, Inc, 2002.

15 Tabor HK, Stock J, Brazg T, et al. Informed consent for whole genome sequencing: A qualitative analysis of participant expectations and perceptions of risks, benefits, and harms. Am J Med Genet A 2012;158A(6):1310-19.

16 Driessnack M, Daack-Hirsch S, Downing N, et al. The disclosure of incidental genomic findings: an "ethically important moment" in pediatric research and practice. J Community Genet 2013:4:435-44.

17 Wade $\mathrm{CH}$, Tarini BA, Wilfond BS. Growing up in the genomic era: implications of whole-genome sequencing for children, families, and pediatric practice. Annu Rev Genomics Hum Genet 2013;14:535-55.

18 Tercyak KP, Alford SH, Emmons KM, et al. Parents' attitudes toward pediatric genetic testing for common disease risk. Pediatrics 2011;127(5):e1288-e95.

19 Abdul-Karim R, Berkman BE, Wendler D, et al. Disclosure of Incidental Findings From Next-Generation Sequencing in Pediatric Genomic Research. Pediatrics 2013:131(3):564-71.

20 Townsend A, Adam S, Birch PH, et al. "I want to know what's in Pandora's box": Comparing stakeholder perspectives on incidental findings in clinical whole genomic sequencing. Am J Med Genet A 2012;158A(10):2519-25.

21 Wilfond BS, Diekema DS. Engaging children in genomics research: decoding the meaning of assent in research. Genet Med 2012;14(4):437-43.

22 Anastasova V, Mahalatchimy A, Rial-Sebbag E, et al. Communication of results and disclosure of incidental findings in longitudinal paediatric research. Pediatr Allergy Immunol 2013;24(4):389-94.

23 Davis DS. The parental investment factor and the child's right to an open future. Hastings Cent Rep 2009;39(2):24-7.

24 Burke W, Antommaria AHM, Bennett $R$, et al. Recommendations for returning genomic incidental findings? We need to talk! Genet Med 2013;15:854-9.

25 Lohn Z, Adam S, Birch PH, et al. Incidental findings from clinical genome-wide sequencing: a review. J Genet Counsel 2014;23:463-73.

26 American College of Medical Genetics and Genomics (ACMG). Incidental findings in clinical genomics: a clarification. Genet Med 2013;15:664-6.

27 Réseau de Médecine Génétique Appliquée (RMGA). RMGA Statement of Principles on the Return of Research Results and Incidental Findings (Summary). Secondary RMGA Statement of Principles on the Return of Research Results and Incidental Findings (Summary) April 2013. http://www.rmga.qc.ca/en/documents/Brochure_ angl_18avril2013_soumisRMGA.pdf

28 Green RC, Berg JS, Grody WW, et al. ACMG Recommendations for Reporting of Incidental Findings in Clinical Exome and Genome Sequencing. Genet Med 2013;15(7):565-74.

29 Borry P, Stultiens L, Goffin T, et al. Minors and informed consent in carrier testing: a survey of European clinical geneticists. J Med Ethics 2008;34(5):370-74.

30 Metcalfe A, Coad J, Plumridge GM, et al. Family communication between children and their parents about inherited genetic conditions: a meta-synthesis of the research. Eur J Hum Genet 2008;16(10):1193-200.

31 Dellve L, Samuelsson L, Tallborn A, et al. Stress and well-being among parents of children with rare diseases: a prospective intervention study. J Adv Nur 2006;53 (4):392-402

32 Forrest $L E$, Curnow L, Delatycki MB, et al. Health first, genetics second: exploring families' experiences of communicating genetic information. Eur JHum Genet 2008:16(11):1329-35.

33 Lipinski SE, Lipinski MJ, Biesecker LG, et al. Uncertainty and perceived personal control among parents of children with rare chromosome conditions: The role of genetic counseling. Am J Med Genet C Semin Med Genet 2006;142C(4): 232-40 